\title{
An analysis of initiation codon utilization in the Domain Bacteria - concerns about the quality of bacterial genome annotation
}

Correspondence

Andrew M. Kropinski

Andrew_Kropinski@

phac-aspc.gc.ca

Received 13 June 2008

Revised 27 June 2008

Accepted 1 July 2008
Andre Villegas ${ }^{1}$ and Andrew M. Kropinski ${ }^{1,2}$

\author{
${ }^{1}$ Public Health Agency of Canada, Laboratory for Foodborne Zoonoses, Guelph, ON N1G 3W4, \\ Canada \\ ${ }^{2}$ Department of Molecular and Cellular Biology, University of Guelph, Guelph, ON N1G 2A3, Canada
}

\begin{abstract}
Using custom software (Inidon) we have examined the initiation codon utilization in 620 complete bacterial genomes downloaded from the National Center for Biotechnology Information (NCBI). The mean utilization of ATG, GTG and TTG codons is 80.1, 11.6 and $7.8 \%$, respectively. In most cases in which similar species or strains have been analysed the utilization percentages of the three initiation codons are remarkably similar, but in certain cases the results exhibit significant differences.
\end{abstract}

While numerous programs are available [e.g. GCUA (McInerney, 1998), OPTIMIZER (Puigbo et al., 2007), ACUA (Vetrivel et al., 2007), E-CAI (Puigbo et al., 2008), CAI Analyser (Ramazzotti et al., 2007), CodonW (http:// codonw.sourceforge.net/culong.html) and Countcodon (Nakamura et al., 2000; http://www.kazusa.or.jp/codon/ countcodon.html)] for the analysis and optimization of codon usage, little has been published on initiation codon usage in bacteria. Surprisingly, the only paper specifically to address this topic was published well before the genomic era (Rudd \& Schneider, 1992). From that paper, one is left with the impression that, at least in the case of Escherichia coli, ATG(AUG) is the predominant initiation codon (92.0\% of characterized genes), while GTG(GUG) functions in $6.7 \%$ of translational starts, and TTG(UUG) accounts for only $1.2 \%$.

We have reexamined the status of initiation codon usage using data from 620 bacterial chromosomes (GenBank data to February 14, 2008). Data on bacterial genomes were downloaded from the GenBank ftp site at the National Center for Biotechnology Information (NCBI; ftp:// ftp.ncbi.nih.gov/genbank/genomes/Bacteria/). Information on the microbial phylum and genome mass was extracted from the genomic flat file $\left({ }^{*}\right.$.gbk), and on $\mathrm{mol} \% \mathrm{G}+\mathrm{C}$ from the FASTA nucleotide ( ${ }^{\star}$.fna) files. Initiation codon usage was determined using Inidon (Initiation Codon; http:// molbiol-tools.ca/Inidon/) software. This program was written as a Java applet and is easily accessible via a Javaenabled web browser. This tool accepts FASTA-formatted gene files $\left({ }^{*}\right.$.ffn - nucleotide coding regions). Inidon goes through each gene in these files and records the number of

A table of results exported from Inidon for 620 bacterial chromosomes is available with the online version of this paper. Access to Inidon software can be obtained at http://molbiol-tools.ca/InitCodon/Supplementary_TableS1.xls. occurrences for every initiation codon encountered. The program reports the total number of genes in the input file, the number of occurrences and the frequency of each encountered initiation codon in decreasing order. The results were then exported into MS Excel (the complete database can be viewed as Supplementary Table S1).

Although the total data show considerable scatter (Fig. 1), analysis using Lowess Spine analysis (GraphPad Software) suggests that the overall base composition of the host genome has little impact on initiation codon utilization between 30 and $65 \mathrm{~mol} \% \mathrm{G}+\mathrm{C}$ (Fig. 1).

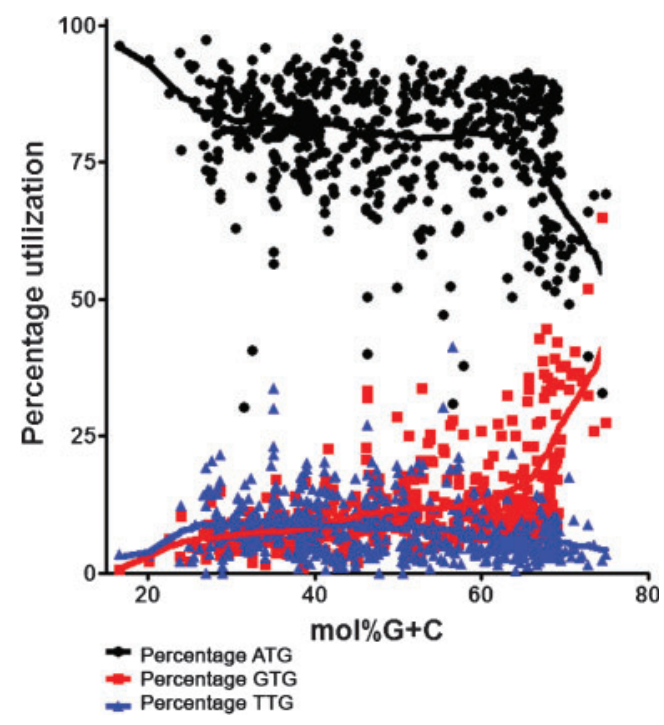

Fig. 1. Utilization of ATG, GTG and TTG initiation codons in 620 bacterial chromosomes as a function of their mol\%G $+\mathrm{C}$ content. 
Table 1. Closely related genomes with significantly differing percentages of ATG initiation codon utilization

CDS, coding sequence.

\begin{tabular}{|c|c|c|}
\hline Genomic pairs & $\begin{array}{c}\text { Percentage utilization } \\
\text { of ATG }\end{array}$ & $\begin{array}{c}\text { Potential CDSs with different } \\
\text { initiation } \operatorname{codons}^{\star} / \text { mean number } \\
\text { CDSs }\end{array}$ \\
\hline Bacillus thuringiensis konkukian & 80.3 & $935 / 4926$ \\
\hline Bacillus thuringiensis Al Hakam & 67.0 & \\
\hline Brucella melitensis $16 \mathrm{M}$ chromosome I & 79.4 & $433 / 2122$ \\
\hline Brucella melitensis biovar Abortus 2308 chromosome I & 63.3 & \\
\hline Burkholderia pseudomallei K96243 chromosome I & 80.3 & $123 / 3587$ \\
\hline Burkholderia pseudomallei 1710b chromosome I & 73.3 & \\
\hline Chlamydophila pneumoniae CWL029 & 82.2 & $57 / 1082$ \\
\hline Chlamydophila pneumoniae TW 183 & 72.7 & \\
\hline Ehrlichia ruminantium str. Welgevonden & 86.4 & $104 / 938$ \\
\hline Ehrlichia ruminantium str. Welgevonden & 71.9 & \\
\hline Legionella pneumophila Corby & 89.4 & $675 / 3073$ \\
\hline Legionella pneumophila Philadelphia 1 & 74.5 & \\
\hline Leptospira interrogans serovar Lai chromosome I & 58.6 & $250 / 3825$ \\
\hline Leptospira interrogans serovar Copenhageni chromosome I & 67.9 & \\
\hline Prochlorococcus marinus MIT 9215 & 80.8 & $197 / 2490$ \\
\hline Prochlorococcus marinus MIT 9303 & 67.7 & \\
\hline Streptococcus pyogenes SSI-1 & 88.2 & $295 / 1880$ \\
\hline Streptococcus pyogenes MGAS2096 & 70.9 & \\
\hline Streptococcus thermophilus LMD-9 & 84.8 & $111 / 1812$ \\
\hline Streptococcus thermophilus CNRZ1066 & 69.9 & \\
\hline Vibrio vulnificus CMCP6 chromosome I & 89.2 & $385 / 3117$ \\
\hline Vibrio vulnificus YJ016 chromosome I & 69.5 & \\
\hline Yersinia pestis Pestoides F & 87.7 & $615 / 3920$ \\
\hline Yersinia pestis KIM & 67.5 & \\
\hline
\end{tabular}

*(Percentage ATG $\times$ number CDSs $)_{\text {organism } 1}-(\text { percentage ATG } \times \text { numberCDSs })_{\text {organism } 2}$

Bacterial genomes with extremely low GC contents tended to exclusively utilize ATG, while at high host mol\%GC the utilization of ATG and TTG decreased and that of GTG increased. The mean utilization of these three codons was ATG, 80.1\%, GTG, $11.6 \%$, and TTG, $7.8 \%$, values considerably different from those reported by Rudd \& Schneider (1992).

In most cases where similar species or strains were analysed, the utilization percentages of the three initiation codons were remarkably similar. In certain cases (see Table 1) the results exhibited significant differences.

In part this may be due to differences in recognizing coding regions, since many of these pairs showed significant differences in the total number of genes. This was not due to the massive presence of pseudogenes, which only had an impact on 'initiation codon' percentages in Mycobacterium leprae and Rickettsia massiliae (see Supplementary Table S1, column M).

In addition, in the case of Mycoplasma gallisepticum, ATT and ATC contributed significantly to initiation codon utilization, yet apparently are not utilized in related species. Examination of the data further suggests that the major discrepancies are due to over or under estimation of the role of TTG codons, and to a lesser extent the utilization of GTG. These results clearly indicate that the identification of initiation codons in bacterial genes is still far from precise and therefore warrants new software developments plus the reexamination, and possible third-party correction, of existing GenBank genomic data.

\section{REFERENCES}

Mclnerney, J. O. (1998). GCUA: general codon usage analysis. Bioinformatics 14, 372-373.

Nakamura, Y., Gojobori, T. \& Ikemura, T. (2000). Codon usage tabulated from the international DNA sequence databases: status for the year 2000. Nucleic Acids Res 28, 292.

Puigbo, P., Guzman, E., Romeu, A. \& Garcia-Vallve, S. (2007). OPTIMIZER: a web server for optimizing the codon usage of DNA sequences. Nucleic Acids Res 35, W126-W131.

Puigbo, P., Bravo, I. G. \& Garcia-Vallve, S. (2008). E-CAI: a novel server to estimate an expected value of Codon Adaptation Index (eCAI). BMC Bioinformatics 9, 65.

Ramazzotti, M., Brilli, M., Fani, R., Manao, G. \& Degl'innocenti, D. (2007). The CAI Analyser Package: inferring gene expressivity from raw genomic data. In Silico Biol 7, 507-526. 
Rudd, K. E. \& Schneider, T. D. (1992).Compilation of E. coli ribosome binding sites. In A Short Course in Bacterial Genetics, pp. 17.19-17.45. Edited by J. H. Miller. Cold Spring Harbor, NY: Cold Spring Harbor Laboratory.
Vetrivel, U., Arunkumar, V. \& Dorairaj, S. (2007). ACUA: a software tool for automated codon usage analysis. Bioinformation 2, 62-63.

Edited by: C. J Dorman 